\title{
SOCIETY OF NORTH AFRICA ON THE EVE OF THE EMPIRE'S WAR WITH THE VANDALS AND ITS ATTITUDE TO JUSTINIAN'S RECONQUISTA
}

\author{
Natalya E. Zolotukhina \\ Belgorod State National Research University, Belgorod, Russian Federation \\ Nikolay N. Bolgov \\ Belgorod State National Research University, Belgorod, Russian Federation
}

\begin{abstract}
Introduction. The article presents an analysis of North African society on the eve of Belisarius's campaign against the vandals in North Africa (533-534). The campaign directed by Justinian under the leadership of Belisarius aimed to return the territory of North Africa to the Roman Empire. Methods. The methodological basis of this work is the concept of the Late Antiquity, the core of which is studying the people's mentality, since the existing work on this issue focuses solely on socio-economic and political cause-and-effect relationships of the further confrontation between the Moorish and Roman tribes. Actually, the methods are the following: the historical-systemic method was the most important (an attempt to analyze the specifics of North African society on the eve of the war with the Vandals). Analysis. We divided North African society into three groups: the Vandals, the Libyans, the Moorish. The last two groups and their attitude towards the inclusion in the Roman Empire were of the greatest interest. Some of the tribes supported Justinian's idea of the Reconquista and fought against the Vandals. Some supported the vandals. Nomadic tribes remained neutral. In our opinion, supporting the military campaign against the Vandals was due not only to economic reasons, but also mental ones. Thus, the research interest was caused by the transition period but not only in relation to the "Late Roman - Early Byzantium" line, but also because the region was romanized (presence of Latin culture, including the language segment), then it was part of the Vandal kingdom, after that - part of the Roman Empire (synthesis of Greek and Latin culture, with the predominance of Greek one). Results. In the course of the campaign against the vandals, North African society was represented by several social groups: the Vandals, the Libyans and the Moorish tribes that have their own cultural characteristics. Some tribes, who were in the Romanized zone (before the arrival of the Vandals), were on the side of Belisarius and fought against the Vandals. With extreme caution, we can say that this was due not only to socio-economic or political reasons, but also to mental ones. In our opinion, Byzantine Africa was a synthesis of Latin and Greek with the prevalence of the latter, and the Romanized population still wanted to feel part of the Roman Empire.
\end{abstract}

Key words: Late Antiquity, Early Byzantium, North Africa, Vandals, Moorish.

Citation. Zolotukhina N.E., Bolgov N.N. Society of North Africa on the Eve of the Empire's War with the Vandals and Its Attitude to Justinian's Reconquista. Vestnik Volgogradskogo gosudarstvennogo universiteta. Seriya 4. Istoriya. Regionovedenie. Mezhdunarodnye otnosheniya [Science Journal of Volgograd State University. History. Area Studies. International Relations], 2019, vol. 24, no. 6, pp. 198-205. (in Russian). DOI: https://doi.org/ 10.15688/jvolsu4.2019.6.16

ОБЩЕСТВО СЕВЕРНОЙ АФРИКИ НАКАНУНЕ ВОЙНЫ ИМПЕРИИ С ВАНДАЛАМИ И ЕГО ОТНОШЕНИЕ К ЮСТИНИАНОВСКОЙ РЕКОНКИСТЕ

\author{
Наталья Евгеньевна Золотухина
}

Белгородский государственный национальный исследовательский университет, г. Белгород, Российская Федерация 


\section{Николай Николаевич Болгов}

Белгородский государственный национальный исследовательский университет, г. Белгород, Российская Федерация

Аннотация. В статье представлен анализ состояния североафриканского общества накануне кампании Велизария против вандалов на территории Северной Африки (533-534 гг.). Экспедиция, направленная Юстинианом под предводительством Велизария, имела цель возвращения территории Северной Африки в состав Ромейской империи. Условно мы выделили в североафриканском обществе три основные этнические группы: вандалы, ливийцы, маврусии. Наибольший интерес вызвали последние две группы и их отношение к включению региона в состав Ромейской империи. Некоторые из племен поддерживали Юстиниановскую идею реконкисты и воевали против вандалов. Некоторая часть поддерживала вандалов. Кочевые племена сохраняли нейтралитет. На наш взгляд, поддержка военной кампании империи против вандалов была обусловлена не только экономическими причинами, но и ментальными. Это было связно с романизацией населения до прихода вандалов. Несмотря на это, военная история (строительство укреплений, отражение набегов и т. д.) региона в VI-VII вв. связана с восстаниями мавританского населения против ромеев ${ }^{1}$. Таким образом, исследовательский интерес вызван исторической транзитивностью не только в отношении линии «позднеримский-ранневизантийский», а также тем, что данный регион был романизирован (наличие латинской культуры, включая языковой сегмент), затем находился в составе Вандальского королевства, после вошел в состав Ромейской империи (синтез греческой и латинской культуры, с преобладанием греческой). Н.Е. Золотухина проанализировала исторические источники с целью выявления основных социальных групп, образующих общество Северной Африки накануне и в момент кампании Велизария. Н.Н. Болгов подготовил разделы «Введение», «Методы», «Источники». Совместно Н.Е. Золотухина и Н.Н. Болгов разработали концепцию работы, акцентировав внимание на транзитивности и определении идентичности социальных групп.

Ключевые слова: Поздняя античность, Ранняя Византия, Северная Африка, вандалы, маврусии.

Цитирование. Золотухина Н. Е., Болгов Н. Н. Общество Северной Африки накануне войны Империи с вандалами и его отношение к Юстиниановской реконкисте // Вестник Волгоградского государственного университета. Серия 4, История. Регионоведение. Международные отношения. - 2019. - Т. 24, № 6. - С. 198205. - DOI: https://doi.org/10.15688/jvolsu4.2019.6.16

Введение. Королевство вандалов занимало 1/9 части территории Северной Африки, или Магриба (территории, расположенные к западу от Египетского диоцеза, не включавшие его) (439-533 (534) гг.). Остальная часть региона, над которой вандалы осуществляли лишь номинальный контроль, была населена мавританскими племенами. Кампания, направленная Юстинианом под предводительством Велизария, носила цель возвращения территории Северной Африки в состав империи. После войны с вандалами военная история (строительство укреплений, отражение набегов и т. д.) региона была связана исключительно с восстаниями мавританского населения в отношении ромеев и позже вторжением арабов. Исследовательский интерес вызван транзитивностью не только в отношении линии «позднеримский - ранневизантийский», а также тем, что регион был романизирован (наличие латинской культуры, включая языковой сегмент), затем находил- ся в составе вандальского королевства, после вошел в состав Ромейской империи (синтез греческой и латинской культуры, с преобладанием греческой) ${ }^{2}$.

Цель работы - рассмотреть основные социальные группы, локализованные на спорной территории накануне и в момент кампании Велизария и их отношение к Юстиниановской идее и практике реконкисты.

Методы. Методологической основой данной работы является концепция Поздней античности Питера Брауна, нашедшая отражение в фундаментальном исследовании «Мир поздней античности» [7], стержнем которой является исследование ментальности народа в ходе смены исторических циклов (ориентация на культуру и религию), поскольку в имеющихся работах в рамках данной проблематики затрагиваются исключительно социально-экономические и политические причинно-следственные связи дальнейшей конфронтации племен маврусиев и ромеев. 
В нашем исследовании наибольшее значение имел историко-системный метод (попытка анализа специфики североафриканского общества накануне войны с вандалами).

Источники. В ходе исследования мы обращались к разным группам источников. В первую очередь это письменные свидетельства современников. Важным источником является труд Прокопия Кесарийского «Война с вандалами» [16]. В сочинении представлена военная, политическая и социально-экономическая характеристика региона. Несмотря на некоторую тенденциозность в описании, Прокопием приведены данные, которые имели значение при исследовании социально-экономической и политической ситуации в регионе, сложившейся накануне войны с вандалами. Также в сочинении представлены культурные особенности мавританских племен. Эти сведения важны для понимания ментальности маврусиев. Следующий источник - поэма африканского поэта и грамматика из Карфагена - Кориппа «Иоаннида» (VI в.), в которой представлены географические, этнографические, религиозные сведения о Северной Африке и мавританских племенах [17]. Дополнительно нами был использован труд Виктора Витенского, благодаря которому можно проследить линию взаимоотношений между вандалами и маврусиями в V в. [19], а также «Хроника» Марцеллина Комита [3].

В ходе исследования мы обращались к Своду гражданского права [10] (Кодекс Юстиниана, Дигесты, Новеллы, Эдикты), к археологическим и эпиграфическим материалам.

Анализ. Вандалы под предводительством Гейзериха заняли Африку в 429 году ${ }^{3}$. В феврале 435 г. они были признаны Валентинианом III как федераты на территории северной Сетифской Мавритании и Нумидии, простиравшейся от Сетифа до Каламы со столицей Гиппоне Регии ${ }^{4}$ [8, p. 244-249; 11, p. 155-170].

Позже, в 439 г., Карфаген был занят вандалами, и император признал их суверенитет над территориями Проконсульской провинции, Бизацены, Триполитании и восточной частью Нумидии. Оставшаяся часть Нумидии и Сетифской Мавритании возвращалась Валентиниану III [8, p. 254-260; 11, p. 171-185]. К 477 г. Королевство вандалов занимало Мавританские провинции, Балеарские острова, Корсику,
Сардинию, а также ряд городов вдоль побережья, например, Септем [11, p. 185-205]. Таким образом, вандалы контролировали Западное Средиземноморье и важные морские торговые пути, за исключением Сицилии, которая находилась под контролем остготов.

В самой Африке территория расселения собственно вандалов была ограничена Проконсульской провинцией и северной частью Бизацены. Общее число вандалов было сравнительно небольшим, необходимо было предотвратить их рассеивание - в общей сложности около 80 тыс., включая алан и готов 5 [19, I. 2]. Также необходимо заметить, что общая численность Вандальской Африки, учитывая мавританское население, могла достигать 2 млн. Таким образом, мы видим, что в численном соотношении вандалы находились в меньшинстве и постоянно пребывали в процессе ассимиляции.

С точки зрения военной организации в Вандальской Африке локализировалось порядка 80 подразделений, в состав которых могло входить от 200 до 250 человек. Также, если мы говорим о военной численности на 533 г., то Прокопий отмечает, что Гелимер получил военную поддержку от мавританских племен [16, IV. 6, 1-3].

В основной части армия вандалов состояла из кавалерии. Их всадники были одеты в кольчуги и ехали в бой со знаменами, украшенными фантастическими животными [17, III. 236-238].

Также стоит отметить, что для ромеев был страшен навык вандалов как моряков, репутация которых возросла благодаря уничтожению двух римских морских экспедиций в 460 и 461 гг, а также их набегам, проведенным вдоль побережья Иллирика и Греции с 470-х годов. Хотя, например, нет никаких подтверждений тому, что вандалы вообще имели в своем корпусе военные корабли [11, p. 208].

Следующая группа населения, которая будет нами рассмотрена - римские африканцы (ливийцы) ${ }^{6}$. Одной из целей кампании Велизария в Северную Африку являлось возвращение римских африканцев (ливийцев) из-под вандалов, и эта формулировка вскоре появляется в ряде документов [16, III. 20, 18-20; 10, vol. II, I. 27, 1, 1]. Однако интерес для дальнейшего исследования вызывает интерпрета- 
ция сведений Прокопия Кесарийского и Кориппа относительно действий ромейских императоров в отношении Африки Джонатаном Конантом [9]. По его мнению, Юстиниановская кампания была направлена не столько «на спасение Африки от вандалов, сколько от мавров» $[9$, p. 252-306].

Велизарий не был уверен в поддержке местного римского населения, и на то был ряд причин, которые мы рассмотрим ниже. В свою очередь Юстиниан, после первых вестей о победах Велизария считал всю Африку провинцией империи, но в действительности власть императора была восстановлена только в восточной части бывшего вандальского государства и на островах [2, c. $130 ; 12$, p. 34-93].

Велизарий, высадившись с армией в местечке Caput Vada, упрекал ромеев за то, что те начали собирать фрукты с деревьев местных собственников, тем самым опасаясь, что такие действия могут привести к тому, что местное население не поддержит ромеев, а примет сторону вандалов [16, III. 16, 1-8; III. 20, 17-20]. Однако местное римско-африканское население не воспринимало ромеев как освободителей. Более того, в ряде городов, в том числе и в Карфагене, жители отказывались от сотрудничества с империей. У Прокопия имеется упоминание о том, что Велизарию пришлось казнить одного из жителей за измену, чтобы отговорить других от сотрудничества с вандалами [16, IV. 1, 8].

На наш взгляд, незаинтересованность в восстановлении имперской власти заключалась в том, что многие представители низшего слоя римско-африканского общества оказались в более выгодном положении при вандалах, чем при ромееях, несмотря на то что римская система налогообложения поддерживалась в той или иной форме и при вандалах.

Наиболее всего от вандалов пострадали крупные землевладельцы. Поселение армии вандалов в Проконсульской провинции и строительство королевского двора в Бизацене и Нумидии повлекли за собой присвоение земли вандалами [16, III. 5, 10-13; 19, I. 13]. Так как земли, принадлежавшие вандалам, были освобождены от налогообложения, высокому налогообложению подверглись те землевладельцы римско-африканского происхождения, которые сохранили свои земли за собой [16, III. 3, 25-27; 5, 14-17].

В 451 г. Валентиниан III наделил землей в Нумидии и Мавритании тех, кто лишился ее в Проконсульской области и Бизацене. Другая часть крупных землевладельцев бежала в Сирию или Италию. Также необходимо отметить, что некоторые из этих людей остались в Африке и процветали. Согласно Виктору Витенскому, Викторин из Гадруме$\mathrm{Ta}^{7}$, являясь проконсулом Карфагена в 484 г., был самым богатым человеком в Африке [19, III. 27]. Однако в регионе все же присутствовала часть римско-африканского населения, которая поддерживала в лице Велизария ромейскую власть.

Как мы видим, отношение римских африканцев к кампании Велизария было неоднозначным. В основном политику империи поддерживали крупные землевладельцы, которые хотели вернуться в состав империи, руководствуясь и идеологическими, и материальными целями. Однако после сокрушения королевства вандалов римско-африканское население было готово объединиться с ромееями в борьбе против мавров. Именно из числа ливийцев Велизарий планировал набрать лимитанов, которые должны были сыграть важную роль при защите Византийской Африки [10, vol. II, I. 27, 2, 8-9].

Мавританские племена (маврусии) - еще одна этно-социальная группа, проживающая на территории Африки [4, с. 79]. Общая территория Северной Африки составляла около 900 тыс. км ${ }^{2}$, в то время как римские провинции Африки, включая Тингитанскую Мавританию ${ }^{8}$, в период наибольшей своей протяженности при Северах ${ }^{9}$ охватывали площадь около 350 тыс. км²; при Диоклетиане эта территория сократилась до 240 тыс. км² $[15$, р. 26]. В этих границах существовали местные племена, говоря на своих языках, поклоняясь своим собственным богам и сохраняя свои племенные структуры.

В «Иоанниаде» читателю представлены две Африки: одна - безмятежно спокойная (римские африканцы), другая - темная и страшная (неримские африканцы), окружающая христианский римский мир, сконцентрированная на окраинах. По мнению Кориппа, эти неримские африканцы казались дикими-дики- 
ми дикарями, живущими за гранью цивилизации [17, I.I, I.54, I.254, II.61, II.109, II.237, IV.51, IV.104]. Отдельно следует отметить, что мавританское варварство являлось ключевым элементом ромейской пропаганды в VI в., и у Кориппа были веские основания изображать маврусиев в максимально темном свете ${ }^{10}$.

В 530-х гг. в Цезарейской Мавритании правителем был Мастинас, или Мастигас, который взимал дань со всей Цезарейской Мавритании за исключением города Кесарии (Цезареи), переданного ромеям. Далее на восток простирались территории Сетифской Мавритании, находившиеся под предводительством Ортая ${ }^{11}$.

Орес находился под управлением Иауды [16, IV. 12, 29]. Эта территория была частью Вандальского королевства с 442 г., но маврусии объявили себя независимыми от вандалов во время правления Гунериха [16, III. 8, 5; IV, 13, 26].

Согласно Прокопию, римские города Тамугади и Багаи, лежащие на равнине к северу от Ореса, были опустошены и покинуты своим населением [16, IV. 13, 26; 19, 7; 19, 20]. Иауда неоднократно вторгался на территорию, которая находилась под контролем Ортая. В 546 г. к Иауде присоединились кочевые племена, находившиеся под предводительством Куцины [16, IV. 25, 2].

Большинство этих кочевников, по-видимому, были из племен левкатов. Впервые триполитанские кочевники появились в Бизацене, вероятно, при Тразамунде (вандальский король в 496-523 гг.), когда они, находясь под предводительством Каваона ${ }^{12}$, нанесли поражение армии вандалов. Накануне вторжения ромеев Лептис Магна и Сабрата были разрушены маврусиями [16, VI. 4, 1-10]. Виктор Витенский отмечает еще одно племя маврусиев, которое проживало в Гафсе и поддерживало ромеев [19, I. 35].

В источниках упоминаются и другие названия племен, но для нас они не представляют особого интереса, поскольку на исторической арене Византийской Африки они не имели значения, так как являлись более мелкими племенными подгруппами племен, указанных нами выше ${ }^{13}$.

С целью понимания специфики ведения военных сражений следует заметить, что мав- русии сражались пешком либо верхом с мечом и маленькими круглыми щитами; также у каждого воина было два коротких копья [16, II. 114-115; 126-137; 150-155]. Они вступали в бой, одетые в легкую тунику и с куском ткани, обернутой вокруг головы ${ }^{14}$ [14, p. 81-95]. Маврусии формировали круглый лагерь с частоколом, в центре которого находились женщины, дети и обоз; по периметру круга размещались верблюды, а сами маврусии занимали позицию между ними. Когда кавалерия врага атаковывала маврусиев, лошади приходили в замешательство от верблюжьего запаха, атакующие отступали, а маврусии выбегали с копьями и контратаковали [16, III. 8, 15-28].

Также следует отметить, что вандалы продолжали римскую практику наделения правителей маврусиев символами, которые соответствовали их должности - серебряный с позолотой жезл и серебряный головной убор, покрывающий не всю голову, но, как венок, отовсюду поддерживаемый серебряными пластинками; белый плащ, застегивающийся золотой пряжкой на правом плече наподобие фессалийской хламиды; белый хитон с вышивкой и золоченая обувь [16, III. 25, 7]. Это обстоятельство имеет большое значение, поскольку, когда ромеи начали кампанию по возвращению Северной Африки в состав империи, вожди маврусиев Мавритании, Нумидии и Бизацены отправили послов к Велизарию, объявили себя подданными императора Юстиниана и дали обещание сражаться в союзе с ромееями.

Прокопий упоминает, что некоторые из вождей предлагали Велизарию в качестве заложников своих детей и просили прислать им по древнему обычаю знаки их власти, поскольку у маврусиев был закон, что никто не имеет права властвовать над ними, прежде чем василевс римлян не пришлет ему, пусть даже будет он врагом римлянам, знаков его власти [16, III. 25, 2-8].

Однако на протяжении VI-VII вв. отношения между ромеями и местными племенами будут сложными. Во-первых, слабость позднеримского, а затем и вандальского контроля в V - начале VI в. позволила развить крупные обособленные мавританские вождества, некоторые из которых находились в «опасной близости» к основным районам ро- 
манизированного африканского населения. К началу VI в. кочевники из Триполитании появляются на юге Бизацены, с чем будут связаны дальнейшие внутренние конфликты между ромеями и маврусиями [13, p. 81-95]. Также политика Юстиниана в отношении рероманизации Африки в VI в. поднимает на поверхность вопрос: насколько сохранилось «римское» за сто лет существования Вандальского королевства на территории Африки.

Выводы. Североафриканское общество в ходе проведения кампании византийцев против вандалов было представлено несколькими этно-социальными группами: вандалами, ливийцами (у Прокопия - африканцы римского происхождения), маврусиями - племенами, имеющие свои культурные особенности в зависимости от ареала обитания (например, кочевники Триполитании, оседлое население Нумидии).

В нашем исследовании особое внимание было уделено двум последним группам и их отношению к вхождению в состав Ромейской империи. Некоторые племена, которые находились в романизированной зоне (до прихода вандалов), выступали на стороне Велизария и воевали против вандалов.

С особой осторожностью, мы можем говорить, что подобное было обусловлено не только социально-экономическими или политическими причинами, но и ментальными (идея сохранения римской идентичности римскими африканцами, которые на протяжении долгого времени находились в составе Вандальского королевства, а затем были рероманизированы), и романизированное население все еще хотело ощущать себя частью Ромейской империи.

\section{ПРИМЕЧАНИЯ}

${ }^{1} \mathrm{O}$ проводимой политике Юстиниана в регионе см.: [5, с. 120-125].

${ }^{2}$ О сегменте латинской культуры в Северной Африке подробнее см.: [1].

${ }^{3} \mathrm{O}$ положении дел в Северной Африке при вандалах см.: [18, p. 29-199].

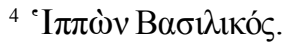

${ }^{5}$ Прокопий предполагает увеличение общей численности населения Вандальского королевства за счет смешанных браков [16, III. 5, 20], однако, по его мнению, на момент военной кампании Велизария их численность не превышала 100 тысяч.
${ }^{6}$ В ряде источников эта формулировка применяется к населению, проживающему на территории Ливии. Согласно Прокопию, ливийцы издревле являлись римлянами, оказались под властью вандалов не по собственной воле и испытали от этих варваров много беззаконий [16, III. 20, 19].

${ }^{7}$ Африканец римского происхождения, занимавший пост при вандалах.

${ }^{8}$ Север современного Марокко.

${ }^{9} 193-235$ гг.

${ }^{10} \mathrm{O}$ полководце Иоанне Троглите, которому посвящена эпическая поэма Кориппа «Иоанниада, или о Ливийской войне», подробнее см.: [6].

${ }^{11}$ На 535 г. Ортай являлся союзником полководца Соломона. Также упоминается у Прокопия во время восстания Стотцы и его сопротивления полководцу Герману [16, IV. 17, 8].

${ }^{12}$ Когда Каваону стало известно, что вандалы идут на него войной, он сделал следующее: приказал своим подчиненным воздержаться от всякой несправедливости, а также от питания, ведущего к распущенной неге, главным же образом от общения с женщинами; затем велел устроить два <укрепленных> лагеря: один для женщин, другой - для мужчин, и пригрозил, что смерть будет наказанием тому, кто пойдет в женский лагерь. У Прокопия упоминается, что он не знал христианского Бога, но полагал, если он могуществен, как говорят, то он, естественно, отомстит оскорбителям его и защитит тех, кто ему служит [16, III. 8, 15-29].

${ }^{13}$ Некоторые из небольших племен обитали в горной местности Папуа. Эти горы располагались у самой границы Нумидии. Прокопий упоминает, что на этой территории проживали варвары-маврусии, с которыми у Гелимера были дружба и взаимный союз [16, IV. 4, 26-27].

${ }^{14}$ На погребальном рельефе в Гирзе в Триполитании изображены два мавра, сражающиеся с копьями; каждый изображен с повязкой на голове, держа маленький круглый щит.

\section{СПИСОК ЛИТЕРАТУРЫ}

1. Болгов, К. Н. Византийская Африка: исторический фон «Иоанниды» Кориппа / К. Н. Болгов, Н. Н. Болгов // Научные ведомости БелГУ. Серия: История. Политология. Экономика. Информатика. -2012. - № 19 (138), вып. 24. - С. 23-32.

2. Кулаковский, Ю. А. История Византии. Т. ІІ. 518-602 / Ю. А. Кулаковский. - СПб. : Алетейя, 2003. $-402 \mathrm{c}$.

3. Марцеллин Комит. Хроника / лат. текст ; пер. и коммент. Н. Н. Болгова. - Белгород : Изд-во БелГУ, 2010. - 230 c. 
4. Третьякова, Н. Е. Маврусии Византийской Африки (VI в.) и их культы / Н. Е. Третьякова // Сборник материалов ежегодной молодежной научной конференции «Молодежь - науке». - Псков, 2014. T. 2. - C. 79.

5. Третьякова, Н. Е. К вопросу об установлении византийской власти в Северной Африке и политике Юстиниана Великого, проводимой в регионе / Н. Е. Третьякова // Науковий вісник Дипломатичної академії України. - 2016. - № 23 (1). - С. 120-125.

6. Третьякова, Н. Е. Иоанн Троглита - полководец Юстиниана / Н. Е. Третьякова // Научные ведомости БелГУ. Серия: История. Политология. 2019. - T. 46, № 1. - C. 37-45. - DOI: https://doi.org/ 10.18413/2075-4458-2019-46-1-37-45.

7. Brown, P. The World of Late Antiquity. From Marcus Aurelius to Muhammad / P. Brown. - L. : Thames and Hudson, 1989. - 216 p.

8. Bury, J. B. History of the Later Roman Empire from the Death of Theodosius I to the Death of Justinian (A.D. 395 to A.D. 565) / J. B. Bury. - N. Y. : Dover Publications, 1958. - $542 \mathrm{p}$.

9. Conant, J. Staying Roman. Conquest and Identity in Africa and the Mediterranean, 439-700 / J. Conant. - Cambridge : Syndics of the Cambridge University Press, 2012. - 458 p.

10. Corpus juris civilis. In 3 vols. Vol. 1. Institutiones, Digesta / ed. P. Krueger, T. Mommsen. Berolini : Apud Weidmannos, 1895. - xxii, 882 p. ; Vol. 2. Codex Justinianus / ed. P. Krueger. - Berolini : Apud Weidmannos, 1895. - xxx, 513 p.; Vol. 3. Novellae/ ed. R. Schoell, W. Kroll. - Berolini : Apud Weidmannos, 1895. - xxii, 810 p.

11. Courtois, C. Les Vandales et l'Afrique / C. Courtois. - Paris : Arts et Métiers Graphiques, 1955. $-455 \mathrm{p}$.

12. Diehl, Ch. L'Afrique byzantine. Histoire de la domination byzantine en Afrique (533-709) / Ch. Diehl. Paris : Ernest Leroux, 1896. -644 p.

13. Goodchild, R. G. The Limes Tripolitanus in the Light of Recent Discoveries / R. G. Goodchild, J. B. Ward-Perkins // Journal of Roman Studies. 1949. - Vol. 39. - P. 81-95.

14. Jones, A. H. M. The Later Roman Empire 284 602. A Social, Economic and Administrative Survey / A. H. M. Jones. - Oxford : Blackwell, 1964. - 1518 p.

15. Pringle, R. D. Sixth-Century Fortifications in Byzantine Africa : An Archaeological and Historical Study : D. Phil. Dis. / R. D. Pringle. - Oxford, 1978. $346 \mathrm{p}$.

16. Procopii Caesariensis. De Bello Vandalico. Lib. 2 / transl. by J. Haury, G. Wirth. - Lipsiae : Teubner, 1963. $-512 \mathrm{p}$.

17. The Iohannis or De Bellis Libycis of Flavius Cresconius Corippus / transl. by G. W. Shea. Lewiston : E. Mellen Press, 1998. - 388 p.
18. Vandals, Romans and Berbers: New Perspectives on Late Antique North Africa / ed. by A. H. Merrills. - Aldershot : Ashgate, 2004. - 347 p.

19. Victor Vitensis. Histoire de la persécution vandale en Afrique : Suivi de La Passion des sept martyrs ; Registre des provinces et des cités d'Afrique / éd. S. Lancel. - Paris : Les belles lettres, 2002. -424 p.

\section{REFERENCES}

1. Bolgov K.N., Bolgov N.N. Vizantiyskaya Afrika: istoricheskiy fon "Ioannidy" Korippa [Byzantine Africa: Historical Background of Corippus' "Iohannis"]. Nauchnye vedomosti Belgorodskogo gosudarstvennogo universiteta. Seriya: Istoriya. Politologiya. Ekonomika. Informatika [Belgorod State University Scientific Bulletin. History. Political Science], 2012, no. 19 (138), vol. 24, pp. 23-32.

2. Kulakovskiy Yu.A. Istoriya Vizantii. T. II. 518 602 [History of Byzantium. Vol. II. 518-602]. Saint Petersburg, Aleteya Publ., 2003. 402 p.

3. Bolgov N.N., ed. Martsellin Komit. Khronika [Marcellinus Comes. Chronicle]. Belgorod, Izd-vo BelGU, 2010.230p.

4. Tretyakova N.E. Mavrusii Vizantiyskoy Afriki (VI v.) i ikh kulty [Moorish of Byzantine Africa and Their Cults (6 ${ }^{\text {th }}$ Century)]. Sbornik materialov ezhegodnoy molodozhnoy nauchnoy konferentsii «Molodezh - nauke» [Collection of Materials of Annual Scientific Conferences: Young People to Science], Pskov, 2014, vol. 2, p. 79.

5. Tretyakova N.E. K voprosu ob ustanovlenii vizantiyskoy vlasti v Severnoy Afrike i politike Yustiniana Velikogo, provodimoy v regione [On the Question of Establishing of Byzantine Power in North Africa and the Policy of Justinian the Great in the Region]. Naukoviy vesnik Diplomatichnoyi akademiyi Ukrayini [Annual Journal of the Diplomatic Academy of Ukraine], 2016, no. 23 (1), pp. 120-125.

6. Tretyakova N.E. Ioann Troglita-polkovodets Yustiniana [John of Troglita - Commander of Justinian]. Nauchnye vedomosti Belgorodskogo gosudarstvennogo universiteta. Seriya: Istoriya. Politologiya [Belgorod State University Scientific Bulletin. History. Political Science], 2019, vol. 46, no. 1, pp. 37-45. DOI: https://doi.org/10.18413/2075-44582019-46-1-37-45.

7. Brown P. The World of Late Antiquity. From Marcus Aurelius to Muhammad. London, Thames and Hudson, 1989. 216 p.

8. Bury J.B. History of the Later Roman Empire from the Death of Theodosius I to the Death of Justinian (A.D. 395 to A.D. 565). New York, Dover Publications, 1958. $542 \mathrm{p}$. 
9. Conant J. Staying Roman. Conquest and Identity in Africa and the Mediterranean, 439-700. Cambridge, Syndics of the Cambridge University Press, 2012. $458 \mathrm{p}$.

10. Krueger P., Mommsen T., eds. Corpus juris civilis. In 3 Vols. Vol. 1. Institutiones, Digesta. Berolini, Apud Weidmannos, 1895. XXII, 882 p.; Krueger P., ed. Vol. 2. Codex Justinianus. Berolini, Apud Weidmannos, 1895. XXX, 513 p.; Schoell R., Kroll W., eds. Vol. 3. Novellae. Berolini, Apud Weidmannos, 1895. XXII, 810 p.

11. Courtois C. Les Vandales et l'Afrique. Paris, Arts et Métiers Graphiques, 1955. 455 p.

12. Diehl Ch. L'Afrique byzantine. Histoire de la domination byzantine en Afrique (533-709). Paris, Ernest Leroux, 1896. 644 p.

13. Goodchild R.G., Ward-Perkins J.B. The Limes Tripolitanus in the Light of Recent Discoveries. Journal of Roman Studies, 1949, vol. 39, pp. 81-95.
14. Jones A.H.M. The Later Roman Empire 284602. A Social, Economic and Administrative Survey. Oxford, Blackwell, 1964.1518 p.

15. Pringle R.D. Sixth-Century Fortifications in Byzantine Africa: An Archaeological and Historical Study: D. Phil. Diss. Oxford, 1978. 346 p.

16. Haury J., Wirth G., eds. Procopii Caesariensis. De Bello Vandalico. Lib. 2. Lipsiae, Teubner, $1963.512 \mathrm{p}$.

17. Shea G.W., ed. The Iohannis or De Bellis Libycis of Flavius Cresconius Corippus. Lewiston, E. Mellen Press, 1998. 388 p.

18. Merrils A.H., ed. Vandals, Romans and Berbers: New Perspectives on Late Antique North Africa. Aldershot, Ashgate, 2004. 347 p.

19. Lancel S., ed. Victor Vitensis. Histoire de la persécution vandale en Afrique: suivi de La Passion des sept martyrs; Registre des provinces et des cités d'Afrique. Paris, Les belles lettres, 2002. 424 p.

\section{Information about the Authors}

Natalya E. Zolotukhina, Postgraduate Student, Department of World History, Belgorod State National Research University, Pobedy St., 85, 308015 Belgorod, Russian Federation, zolotukhina@bsu.edu.ru, https://orcid.org/0000-0001-7709-4920

Nikolay N. Bolgov, Doctor of Sciences (History), Professor, Head of the Department of World History, Belgorod State National Research University, Pobedy St., 85, 308015 Belgorod, Russian Federation, bolgov@bsu.edu.ru, https://orcid.org/0000-0003-0478-5565

\section{Информация об авторах}

Наталья Евгеньевна Золотухина, аспирант кафедры всеобщей истории, Белгородский государственный национальный исследовательский университет, ул. Победы, 85, 308015 г. Белгород, Российская Федерация, zolotukhina@bsu.edu.ru, https://orcid.org/0000-0001-7709-4920

Николай Николаевич Болгов, доктор исторических наук, профессор, заведующий кафедрой всеобщей истории, Белгородский государственный национальный исследовательский университет, ул. Победы, 85, 308015 г. Белгород, Российская Федерация, bolgov@bsu.edu.ru, https://orcid.org/0000-0003-0478-5565 